\title{
Estimation of dog population and dog bite risk factors in departments of San Pedro and Bouake in Côte d'Ivoire
}

\author{
Vessaly Kallo $^{\mathrm{a}, \mathrm{b}, \mathrm{c}, *}$, Moussa Sanogo ${ }^{\mathrm{d}}$, Marcel Boka ${ }^{\mathrm{a}, \mathrm{e}}$, Komissiri Dagnogo $^{\mathrm{a}, \mathrm{f}}$, Mathilde Tetchi ${ }^{\mathrm{g}}$, \\ Sylvain Traorée, ${ }^{\mathrm{h}, \mathrm{i}}$, Monique Lechenne ${ }^{\mathrm{j}, \mathrm{k}}$, Felix Gerber ${ }^{\mathrm{k}}$, Jan Hattendorf ${ }^{\mathrm{j}, \mathrm{k}}$, Jakob Zinsstag, ${ }^{\mathrm{j}, \mathrm{k}}$, \\ Bassirou Bonfoh ${ }^{\mathrm{h}, \mathrm{j}, \mathrm{k}}$ \\ ${ }^{a}$ Direction des Services Vétérinaires (DSV), Abidjan, Côte d'Ivoire \\ ${ }^{\mathrm{b}}$ Ecole Inter Etat des Sciences et de Médecine Vétérinaires (EISMV), Dakar, Senegal \\ ${ }^{\mathrm{c}}$ Université Cheikh Anta Diop de Dakar, Sénegal \\ ${ }^{\mathrm{d}}$ Laboratoire National d'Appui au Développement Agricole, Côte d'Ivoire \\ ${ }^{\text {e } C e n t r e ~ d ' E n t o m o l o g i e ~ M e ́ d i c a l e ~ e t ~ V e ́ t e ́ r i n a i r e ~(C E M V), ~ B o u a k e ́, ~ C o ̂ t e ~ d ' I v o i r e ~}$ \\ ${ }^{\mathrm{f}}$ Direction des Abattoirs et de l'Hygiène Alimentaire du DAA, Côte d'Ivoire \\ ${ }^{\mathrm{g}}$ Institut National de l'Hygiène Publique (INHP), Côte d'Ivoire \\ ${ }^{\mathrm{h}}$ Centre Suisse de Recherche Scientifique (CSRS), Côte d'Ivoire \\ ${ }^{\mathrm{i}}$ Université Peleforo Gon Coulibaly de Korhogo \\ ${ }^{\mathrm{j}}$ Swiss Tropical and Public Health Institute, P.O.Box, 4002 Basel, Switzerland \\ ${ }^{\mathrm{k}}$ University of Basel, Basel, Switzerland
}

\section{A B S T R A C T}

Rabies is endemic in Côte d'Ivoire and was identified in January 2017 as a priority zoonosis by all stakeholders in public health. A well-designed integrated national rabies control is essential to attain the objective of zero human deaths from dog rabies by 2030 . The current study describes the complementary elements of dog bite risk factors and the dog population estimate that are relevant for planning sustainable interventions.

We conducted a transverse survey in 8'004 households in the departments of San Pedro (4'002) and Bouaké (4'002), covering both rural and urban areas. The doghousehold ratio was estimated at one dog for three households (0.33) or one dog for 20 people (0.05).

The owned canine population on a national level was estimated at 1'400'654 dogs (range 1'276'331 to 1'535'681). The main dog bite risk factors were dog ownership, being male, and living in urban San Pedro Department.

The results lay a foundation for public engagement and further steps for mass vaccination of the household dog population to reach vaccination coverage of at least $80 \%$. Stakeholders further recommend raising awareness of dog owners, reinforcing knowledge in school children and young boys, and behavior changes towards domestic animals.

\section{Introduction}

Rabies is a neglected tropical disease that causes on average $59^{\prime} 000$ human deaths each year worldwide, especially in poor and vulnerable populations (Hampson 2015). In Africa and Asia, 99\% of these deaths are due to dog rabies (WHO, 2005).

Rabies has been successfully eliminated in the United States of Amercia through intensive mass vaccination and population sensitization from the end of World War II through the 1970s (Fehlner, 2018). Considerable efforts have been made in Latin America to combat rabies, despite its persistence in Haiti and Bolivia (Schneider et al., 2007, GARC, 2012). In Europe, most Western and Central European countries have been successful in eliminating rabies from domestic carnivores (Bourghy et al., 2015). This progress recorded in control contrasts with the situation in Africa and in Asia, where rabies persists (Lembdo and Al., 2010), due to numerous obstacles including difficulties of owners to vaccinate their dogs, insufficient epidemiological surveillance of rabies, insufficient community engagement, insufficient resources of the veterinary services and lack of information on the dog population (Lembdo and Al., 2010)

As in many African countries, rabies remains a public health problem in Côte d'Ivoire. Low reporting gives an average of 18 deaths per year (Côte d'Ivoire, 2016a), with more than $10^{\prime} 000$ people exposed and referred to different sites of the Institute of Public Hygiene per year. In addition more than $40 \%$ of dog bite victims do not complete post-exposure prophylaxis treatment. The annual cost of rabies in Côte d'Ivoire was estimated to be about 41 million USD (Hampson, 2015).

Each year vaccination campaigns are organized in the country

\footnotetext{
* Corresponding author.

E-mail address: vessalykallo@yahoo.fr (V. Kallo).
} 
around World Rabies Day, but the number of vaccinated dog only reaches about 1'000 per region (Côte d'Ivoire, 2014a, 2015b, 2016b). The population of domestic carnivores remains unknown, although it is established that mass vaccination campaigns should cover at least $70 \%$ of the dog population for elimination of the disease (Zinsstag, 2009).

Despite long neglect in African countries, rabies was recently recognized as a priority zoonosis (Zoonosis prioritization report in Côte d'Ivoire, 2017). It is, therefore, necessary to develop a national rabies control strategy in Côte d'Ivoire. The development of such a strategy should be based on reliable indicators and epidemiological knowledge such as risk factors for rabies transmission and an accurate estimate of the dog population. Such an estimation of the dog population is fundamental for effective implementation of a mass dog vaccination strategy. According to the five stage Stepwise Approach towards Rabies Elimination (SARE) tool, knowledge on the dog population is essential to move from stage one to stage two (GARC, 2018). Consequently, the objective of this study was to estimate the dog population and assess exposure and dog bite risk factors in Côte d'Ivoire.

\section{Methodology}

\subsection{Study area}

This study was conducted among households in the departments of San Pedro and Bouaké, respectively in southwest and central Côte d'Ivoire. The human population of the two sites are $630^{\prime} 000$ inhabitants for San Pedro and 680'000 inhabitants for Bouaké (RGPH, 2014b). These study sites were chosen because in San Pedro a high number of human cases were registered, with 10 cases between 2006 and 2015 (Côte d'Ivoire 2016a), while Bouaké had the highest number of dog bite victims in Côte d'Ivoire, with the most cases of animal rabies in 2015.

\subsection{Sampling plan}

This cross-sectional household study used cluster sampling with selection probability proportional to cluster size and stratified by rural/ urban and study area. In urban areas, 99 geo-reference points were hazardly selected in each department. Of these, 40 points were randomly selected to reach the expected number of households. Investigations were conducted in 50 households for each geo point in the different cities. In the rural areas of each department, 46 villages were randomly selected using data from the last general population census (2014) of Côte d'Ivoire. Of the 46 villages, 40 were included, with 50 households randomly selected in each village. For the household study, we considered a bite incidence of 3.3 per 1000 person-years (Frey et al., 2013). Standard sample size formulas were not considered due to the low number of bites, meaning the intra-class correlation coefficient would be low. Therefore, we performed simulations considering various bite incidences between 2 and 13 bites per 1000 person-years to estimate the sample size. Assuming five members per household in urban areas and seven in rural areas, a sample size of 6-12'000 people was a good compromise between statistical precision and logistical feasibility (Bennet and Al, 1991). Thus we had a target of at least 4000 households per Department, including at least 2000 households each in rural and urban areas, for a total of at least 8000 households.

\subsection{Preparation of the investigation}

Each investigator was trained and obtained a Rabies Trainer Certificate. They were vaccinated against rabies, and then pre-tested the questionnaire in two of the selected sites. Following the pretest, the questionnaire was adapted and finalized.

Each investigator was provided with a tablet for data entry and a spare battery. Three mobile phones, internet connection (wifi Pocket) and three motorcycles were provided for each team in the rural areas.
A timetable was established for each team. In case a household could not be accessed for any reason, the following household was chosen. The reason was noted in the tablet data collection system.

In rural areas, villages were subdivided into five areas and each investigator had 10 households to investigate after identification of the starting point by the team. Calculated number of steps was two in the rural areas. households are selection every second household.

In urban areas, from the list of 99 geo-points selected randomly the supervisor chose a starting point and most appropriate direction for the investigators. Calculated steps for households in the urban areas was three.

\section{Data collection}

The household data was collected using the ODK platform. Interviews were conducted in French and if necessary in local language. The collected information was the number of people, ownership of dogs or cats, animal vaccination status, and reasons for non-vaccination of animals. We also collected information on bite victims: age, gender, help seeking, time to consultation and reasons for delay, as well as the place and circumstance of the bite incident, and the site and nature of the bite wound.(Fig. 1.)

The information on the biting animal was: species, its fate, its vaccination status. Household data were collected from June 16th to July 25th, 2016.

\subsection{Identification of risk factors}

After a descriptive analysis of the data, associations between bite occurrence and victim and household characteristics were assessed using the Chi-square test: age of victim, sex of victim, location of victim, presence of a dog in the household. Variables presenting an independent association $(p<0.05)$ with the response variable (bite) were included in a multivariate logistic model to identify the explanatory variables.

\subsection{Estimation of the dog population}

Risk factors for dog bites were estimated using Generalized Estimating Equation (GEE) models for Poisson distributed count data to account for the cluster survey design. The logarithm of the person-time, calculated as the number of household members multiplied by the recall period, was included as an offset variable. To account for the observed recall bias, which increased with increasing household size, we weighted the households in the analysis so that each household contributes similarly to the estimate irrespectively of the person time.

The density of the canine population was expressed in number of dogs per household then per person in the surveyed household. We thus estimated the density of the canine population by a regression model based on a Poisson's law, from the equation of the following model:

$\exp (A) *(\exp (B) *$ number of households

where A and B are the coefficients obtained from the regression model.

This model was used to account for the highly dispersed nature of the distribution of dogs. This allows an estimate of the population in the household. For estimation of the total dog population, $10 \%$ of $\operatorname{dog}$ population in the household was added to the total estimated population (Kayali u, 2003).

\subsection{Ethical consideration}

This work received ethical approval (N / Ref: 072 / MSHP / CNERkp) from the National Ethics Committee of Côte d'Ivoire. The agreement of the Northwest and Central Ethics Committee of Switzerland was also obtained (Ethics Committee of North Western and Central Switzerland (EKNZ) Basec 2016-00,220). In each Department, an information note 


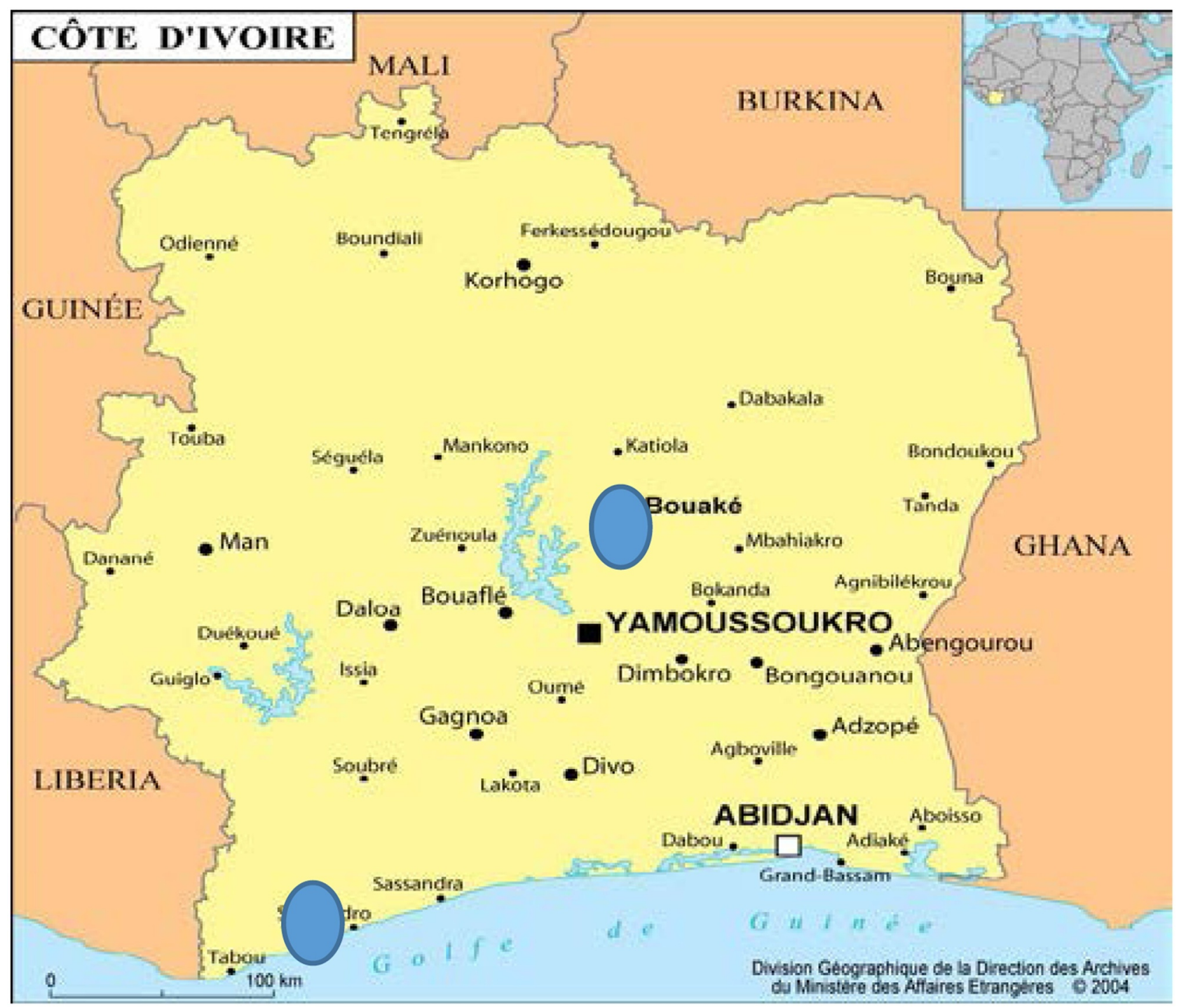

Fig. 1. Area of the study.

prepared by the prefects for local authorities was made available to the investigation teams. The GAVI project offered the Ministry of Health and Public Hygiene anti-rabies vaccine and immunoglobulin, as recommended by WHO for post-exposure treatment of bite victims.

\section{Results}

\subsection{Human and dog population characteristics}

In total we interviewed 8'004 households accounting for 59'174 persons. In the Department of Bouaké, the median number of household members was 7 and in San Pedro 6 (Table 1).The 8'004 households owned a total of 2'370 dogs. The overall proportion of dog was $79.6 \%$ of dogs in rural areas compared to $21.4 \%$ of dogs in urban areas. In the Department of San Pedro, the dog population of the 2'001 households investigated in the rural area is estimated at 544 dogs, representing $70 \%$ and that of the 2001 households investigated in the urban area is estimated to 277 dogs, representing $30 \%$ of the dog population in the households investigated. In the department of Bouaké, the rural dog population of the 2003 households investigated was $1341 \mathrm{dogs}$, or $82.9 \%$, and that of the 1'999 urban households was estimated at 258 dogs, or $16.1 \%$ of the dogs estimated in the Department of San Pedro. (Table 2).

\subsection{Dog vaccination coverage}

The reported number of vaccinated dogs was 280 , representing a vaccination coverage of $12 \%$ among which only 133 could be confirmed with vaccination cards, representing a vaccination coverage of $6 \%$. At the urban level, out of a total of 485 dogs, there were 110 vaccinated dogs, representing vaccination coverage of $23 \%$. At the rural level, out of a total of 1885 dogs counted, 23 were vaccinated, representing $1 \%$ vaccination coverage.

In the Department of San Pedro, out of a total of 771 dogs reported in the households visited, there were 56 vaccinated dogs, for an immunization coverage of $7 \%$. Vaccination coverage in households visited in rural and urban areas was $4 \%$ and $29 \%$, respectively.

In the Department of Bouaké, out of a total of 1599 dogs counted, 77 were vaccinated. This corresponded to a vaccination coverage rate of $5 \%$. Vaccination coverage in households visited in rural and urban areas was $3 \%$ and $30 \%$, respectively.

\subsection{Estimation of the national dog population}

The model used provided an average of 0.33 dogs per household [CI 0.30 - 0.36]. The estimate of dog population in Côte d'Ivoire, according to the latest census (RGHP, 2014) registering 4172,000 households, 
Table 1

Characteristics of the study population.

\begin{tabular}{|c|c|c|c|c|c|}
\hline Characteristic & total & Bouaké & San Pedro & rural & urban \\
\hline Number households(hh) & 8004 & 4002 & 4002 & 4004 & 4000 \\
\hline Persons/hh [median (IQR)] & $6(4-9)$ & $7(4-10)$ & $6(4-9)$ & $7(5-11)$ & $6(4-8)$ \\
\hline Eduction $[\mathrm{N}(\%)]^{\mathrm{a}}$ & $4682(58 \%)$ & $2355(59 \%)$ & $2327(58 \%)$ & $1915(48 \%)$ & 2767 (69\%) \\
\hline hh with dogs [N (\%)] & $1429(18 \%)$ & $911(23 \%)$ & $518(13 \%)$ & $1061(26 \%)$ & $368(9 \%)$ \\
\hline Dogs/hh [mean] & 0.3 & 0.4 & 0.19 & 0.47 & 0.12 \\
\hline Dogs total $[\mathrm{N}]$ & 2370 & 1599 & 771 & 1885 & 485 \\
\hline \multicolumn{6}{|l|}{ Dogs vaccinated (DV)(\%) } \\
\hline DV reported & $280(12 \%)$ & $167(10 \%)$ & $113(15 \%)$ & $88(5 \%)$ & $192(40 \%)$ \\
\hline DV confirmed (last yr) & $133(6 \%)$ & $77(5 \%)$ & $56(7 \%)$ & $23(1 \%)$ & $110(23 \%)$ \\
\hline
\end{tabular}

a including Koranic school.

would be between 1276,331 and 1535,681 in households in Côte d'Ivoire, for a dog population average of 1400,654 . Also taking into account the dogs outside of households, the total dog population increases to between 1403,964 and 1689,249 in Côte d'Ivoire. This translates to a ratio of one dog for 20 people in Côte d'Ivoire, or a dogto-human ratio of 0.05 .

\subsection{Risks factors for dog bites}

Out of 8004 households, 116 dog bite victims were estimated. In rural areas, there were 65 victims, representing $56 \%$ of the victims recorded. In urban areas, 51 victims were registered, representing $44 \%$. The Department of Bouaké recorded 51 bite victims (44\% of total victims) while the Department of San Pedro recorded 65 victims (56\% of total victims). The Bouake urban area registered 13 victims and the rural area 38 victims, $25 \%$ and $75 \%$ of total Bouaké bite victims, respectively. In San Pedro, the urban area registered 45 victims and the rural area 20 victims, with $70 \%$ and $30 \%$ of total San Pedro bite victims, respectively.

Among bite victims, $41 \%$ were female and $59 \%$ were male, while $51 \%$ of victims were under 15 years of age.

We estimated a dog bite incidence of 2 per 1000 person years (95\%CI : 1,6-2,4).

The most important explanatory variables for risk of dog bite at the household level were owning a dog ( $\mathrm{p}$ 0.001), living in urban San Pedro (p 0.044) and being male (p 0.023).

\section{Discussion}

This study is to our knowledge, the first to estimate the size of the dog population in Côte d'Ivoire. This estimate of the size of the dog population is fundamental to the development of a national rabies control program. indeed, it is the prerequisite for the organization of a mass dog vaccination campaign, with the objective to reach the coverage by $70 \%$ required for the elimination of rabies (OIE, 2015). It permits to assess the needs in resources required to organize a national vaccination campaign for the dog population. In addition, after the implementation of the vaccination campaign, this information is essential to assess its effectiveness in terms of vaccination coverage.
Determining the risk factors associated with rabies is decisive for the implementation of an effective control strategy. It also enables to set a better communication with the populations most exposed to risk.

\subsection{Size of the dog population}

The size of the dog population that we have estimated is 15 times larger than that given by the official services (OIE, 2012). This same observation was made by Mbilio (2018), who observed that the size of the dog population estimated during a survey in the Congo was 10 times larger than that of the official services. In addition, our study showed that there are 4 times more dogs in rural households, or $79.6 \%$ of the dogs counted. Despite the fact that the number of households surveyed in the rural area (4000) was practically equal to that in the urban area (4004). A similar finding was made by Davlin et al., (2012). They found through a literary review, that the dog population of the rural area was generally higher than that of the urban area although the density per $\mathrm{km} 2$ was low. This difference in size of the dog population between rural households and urban ones could be linked to sociocultural and religious aspects. Indeed, Amalaman et al. (2019) asserts that the Baoule natives use the dog for various reasons, that is to say hunting, guarding, but also for mystical rituals. Other authors like Mindekem (2005) and Kabeta (T 2015) have found that households in Christian communities have more dogs than those in Muslim communities.

A limitation of our study is that the method used to estimate the canine population did not take into account the population of stray dogs. However, studies by Davlin et al. (2012), Mindekem (2005), Monique (2016), Kabeta (2015), have shown that the proportion of stray dogs was low in Sub-Saharan Africa. However, due to the similarity with the human to Dog Ratio found by Mindekem (2005) in Chad, we used a similar proportion of $10 \%$ of stray dog population to estimate the total dog population. However, the Chadian estimate is from urban areas and a different cultural background, which might over or underestimate the true\% of stray dogs in Côte d'Ivoire. For instance, another study of a large scale vaccination campaign in Chad reported $14 \%$ stray dogs (Léchenne et al., 2016). It seems essential to carry out a study on the size of stray dogs in Côte d'Ivoire.

Table 2

Risk factors for bites, household level.

\begin{tabular}{|c|c|c|c|c|c|c|c|c|}
\hline Variable & $\mathrm{N} \mathrm{hh}$ & pers-yrs & bites & inc & IRR & $95 \%-\mathrm{CI}$ & mIRR & m95\%-CI \\
\hline Rural & 4004 & 33,519 & 65 & 1.94 & & & & \\
\hline Urban & 4000 & 25,655 & 51 & 1.99 & 1.38 & $(0.9-2.2)$ & 1.56 & $(0.9-2.6)$ \\
\hline Bouaké & 4002 & 32,077 & 51 & 1.59 & & & & \\
\hline San Pedro & 4002 & 27,097 & 65 & 2.4 & 1.59 & $(0.9-2.7)$ & 1.76 & $(1-3)$ \\
\hline No dog & 6575 & 45,192 & 68 & 1.5 & & & & \\
\hline Observed dog & 1429 & 13,982 & 48 & 3.43 & 2.12 & $(1.3-3.5)$ & 2.66 & $(1.5-4.7)$ \\
\hline hh head no educ & 3322 & 25,482 & 44 & 1.73 & & & & \\
\hline hh head any educ & 4682 & 33,692 & 72 & 2.14 & 1.5 & $(0.9-2.4)$ & 1.4 & $(0.9-2.3)$ \\
\hline
\end{tabular}




\subsection{Dog bite risk factors in the households}

Our results showed that 116 bites occurred in the 8004 Households, or a bite rate of 2 per 1000 inhabitants. This bite rate is lower than the annual bite incidence calculated by MBilio (2019) in the Congo which was 5.2 per 1000 person. However, it is higher than the incidence calculated in Mali which was 0.5 / 1000 (Keita et al., 2019). The bite rate observed in rural areas is almost identical to that in rural areas, around 2 per 1000 . This similarity of bite incidence between rural and urban areas is not observed in Asian countries where the incidence of bites was much higher in rural areas. In Cambodia and Bangladesh, the incidence of bites was 48.4 / 1000 (Ponsich, 2016) and 72.9 / 1000 respectively (Sharma, 2016). The most important bite risk factors in our study was dog ownership and being male. This result is comparable to that of Mbilo (2019) who found that canine possession was positively correlated with the incidence of bite in the Congo. In addition, our study did not identify age as a predominant risk factor for bite in the household, although $51 \%$ of male bite victims are under the age of 15 . Tetchi (2019) also observed that sex was one of the most important risk factors for bite identified in the human rabies center of Bouaké in Côte d'Ivoire. Furthermore, age is above all a predominant risk factor in cases of human rabies, in fact the WHO (2019) states that children aged 5 to 15 are the most frequent victims of rabies. In Côte d'Ivoire, age is becoming a major risk factor for victims of rabies. Indeed, the official report of the Côte d'Ivoire (2019) reported 27 rabies victims, including 15 children, or $55 \%$. Children are the most at risk victims of rabies because of their size which exposes them to the most risky bites and they may not inform their parents (shen $\mathrm{J}$ et al. 2017). In addition, they do not know the body language of animals (Spiegel, 2000). As a result, Coleman and Hay (2008) showed in Australia that children should be trained to behave appropriately and recognize the emotions of dogs and Increasing awareness through games would improve their behavior toward dogs and avoid dangerous situations faced by children.

\subsection{Vaccination coverage}

The overall rabies vaccination coverage that we reported was $12 \%$, of which only $6 \%$ was certified by the presence of a valid vaccination record. This vaccination coverage is very low compared to the $70 \%$ rate required for canine elimination (OIE, 2015). The vaccination coverage rate was very low in households in the areas under studied, particularly in the rural ones. These areas experienced very limited mass vaccination campaigns of the dog population. Even when they were implemented, these departments received less than 1000 doses for the entire department (Dsv, 2016). This is explained by the weakness of the resources allocated by the Ministry of Livestock and Fishery Resources for the control of animal diseases (PVS, 2012). In addition, populations in household are insufficiently informed about the danger posed by rabies and neglect their responsibility towards dogs. Indeed, a study conducted by Tiembré (2014) in Côte d'Ivoire showed that $71.9 \%$ of heads of household were unaware of the signs of rabies. In addition, the lack of veterinary posts, that is to say an insufficient health network in Côte d'Ivoire was notified by the evaluation of the Performance of veterinary services in 2012. The lack of veterinary posts in these areas makes it difficult for dogs owners to have access to veterinary services. The low vaccination rate of the dog population explains the endemic nature of rabies in the study areas (Côte d'Ivoire, 2016b). In a similar survey carried out in the Democratic Republic of Congo, Mbilo (2019) reported $24 \%$ of vaccinated animals, of which only $11 \%$ had been confirmed by the presentation of a valid vaccination card. Kazadi et al. (2019) explained that this weak vaccination in the Congo Republic was due to the owner's income and the value of the animal. Indeed, he found that middle and high income owners were willing to pay for their valuable dogs. In addition, in Uganda, Wallace et al. (2017) highlighted the importance of poverty in the villages regarding the low immunization coverage. The poorest villages had a vaccination coverage rate less than $15 \%$ and the rate of animals suspected of dying from rabies was high.

\section{Conclusion}

This dog population estimate in rural areas in Côte d'Ivoire is very important for socio-cultural reasons. However, this population remains poorly vaccinated, which constitutes a significant risk factor for the human population in both rural and urban areas. Households with dogs have the highest risk of being bitten. Proper awareness of dog owners and improved knowledge for children is undoubtedly required. Special emphasis should be placed on mass immunization of the dog population in rural areas, without excluding urban area, as the observed vaccination coverage remains very low. Effective campaigns must be based on the support and effective participation of the rural populations.

\section{Autors statement}

Jacob Zinsstag: Conceptualization, Methodology, validation. Bassirou Bonfoh: Conceptualization, Methodology, validation. Kallo Vessaly. Conceptualisation, Writing - Original draft preparation. Sanogo Moussa: Data Analysis. Boka Marcel: Visualization, Investigation. Jan Hattendorf: Conception, Methodology, analysis, validation, Felix Gerber: Data collection, Software, Methodology Mathilde Tetchi : Conceptualisation, Data collection, Dagnogo Komissiri: Data collection, Data Analysis, Traore Sylvain: Data collection, Data Analysis. Monique Lechenne : Conceptualization, Methodology and supervision.

\section{Declaration of Competing Interest}

None.

\section{Supplementary materials}

Supplementary material associated with this article can be found, in the online version, at doi:10.1016/j.actatropica.2020.105447.

\section{References}

Djedou Martin, Amalaman, Sylvain 2, Traore, Vessaly, Kallo, et al., 2019. Déterminants socio-culturels et institutionnels de la collaboration intersectorielle dans la lutte contre la rage: cas de la Côte d'Ivoire » Acta tropica.

Bennett, S., Woods, T., Liyanage, W.M., Smith, D.L, 1991. A simplified general method for cluster-sample surveys of health in developing countries. World Health Stat. Q. Rapp. Trimest. Stat. Sanit. Mond. 44 (3), 98-106.

Côte d'Ivoire, 2014b. Recensement général des populations et de l'Habitat (RGHP) en Côte d'Ivoire. Rapport final INS.

Côte d'Ivoire, 2015. Ministère des Ressources Animales et Halieutiques, Rapport d'activités de la Direction des Services Vétérinaires. Abidjan.

Côte d'Ivoire, 2016a. Ministère de L'hygiène Publique et de Santé, Rapport d'activité de L'institut National de L'hygiène Publique. Abidjan.

Côte d'Ivoire, 2016b. Ministère des Ressources Animales et Halieutiques, Rapport d'activités de la Direction des Services Vétérinaires. Abidjan.

Côte d'Ivoire, 2017. Rapport de priorisation des zoonoses en Côte d'Ivoire. Février.

Côte d'Ivoire, 2014a. Ministère des Ressources Animales et Halieutiques, Rapport d'activités de la Direction Des Services Vétérinaires. Abidjan.

Fehlner, C., Gardiner, 2018. Rabies control in North America-past, present and future. Rev. Sci. Tech. Off. Int. Epiz. 37 (2), 421-437.

Côte d'Ivoire, 2019. Ministère De L'hygiène Publique Et De Santé, Rapport d'activité de L'institut National de L'hygiène Publique. Abidjan.

Davlin, S.L., Vonville, H.M., 2012. Canine rabies vaccination and domestic dog population characteristics in the developing world: a systematic review. Vaccine 30 , 3492-3502 [CrossRef] [PubMed].

Frey, J., Mindekem, R., Kesseley, H, 2013. Survey of animal bite injuries and their management for an estimate of human rabies deaths in N'Djamena, Chad. Trop. Med. Int. Health: TM \& IH 18, 1555-1562. https://doi.org/10.1111/tmi.12202.

GARC: 2018Global alliance for rabies control:https://caninerabiesblueprint.org/A stepwise-approach-to-planning?lang $=$ en.

Hampson, K., Coudeville, L., Lembo, T., Sambo, M., Kieffer, A., et al., 2015. Estimating the global burden of endemic canine rabies. PLoS Negl. Trop. Dis. 9, e0003709. https://doi.org/10.1371/journal.pntd.0003709 PMID: 25881058.

Kazadi, E.K., Marcotty, T., Muylkens, B.;., et al., 2019. Factors of rabies maintenance in dog population in Kinshasa, Democratic Republic of Congo (DRC). Int. J. Infect. Dis. 
79, 56 [CrossRef]

Kabeta, T., Deresa, B., Tigre, W., et al., 2015. Knowledge, attitudes and practices of animal bite victims attending an anti-rabies health center in Jimma Town. Ethiopia PLoS Negl. Trop. Dis. 9 (6), e0003867. https://doi.org/10.1371/journal.pntd. 0003867. eCollection. Jun 262015.

Keita, Z.G.F., Léchenne, M., Thiero, O., et al., 2019. Burden of rabies in Mali. Acta Trop. Lembo, T., Hampson, K., Kaare, M.T., et al., 2010. The feasibility of canine rabies elimination in Africa: dispelling doubts with data. PLoS Negl. Trop. Dis. 4 (2), e626. https://doi.org/10.1371/journal.pntd.0000626.

Mbilo, C., Kabongo J, B., Pyana P, P., et al., 2019. Dog ecology, bite incidence, and disease awareness : a cross-sectional survey among a rabies-affected community in the democratic republic of the Congo. Vaccines 7, 98. https://doi.org/10.3390/ vaccines7030098.

Mindekem, U, Kayali, N., Yemadji, A.G., Ndoutamia, J., 2005. Zinsstag - La démographie canine et son importance pour la transmission de la rage humaine à N'djaména. Med. Trop. 65, 53-58.

Lechenne, M., Oussiguere, A., Naissengar, K., Mindekem, R., et al., 2016. Operational performance and analysis of two rabies vaccination campaigns in N'Djamena, chad. Vaccine 34, 571-577.

OIE, 2015. In: Report of the Rabies Global Conference. GENEVA, SWITZERLAND. 10-11 December.

OIE : Rapport de l'évaluation des performances des services vétérinaires. 2012.

Ponsich, A., Goutard, F., Sorn, S., Tarantola, A., 2016. A prospective study on the incidence of dog bites and management in a rural Cambodian, rabies-endemic setting. Acta Tropica 160, 62-67 [CrossRef] [PubMed].

Sharma, S., Agarwal, A., Khan, A.M., Ingle, G.K., 2016. Prevalence of dog bites in rural and urban slums of delhi: a community-based study. Ann. Med. Health Sci. Res 6, 115-119 [PubMed].

Shen, J., Rouse, J., Godbole, M, Wells, H.L., et al., 2017. Systematic review: interventions to educate children about dog safety and prevent pediatric dog-bite injuries: a metaanalytic review. J. Pediatr. Psychol. 42, 779-791 [CrossRef].

Tectchi, M., Coulibaly, B., Kallo, V., et al., 2019. Impact of the Thai Red Cross protocol on compliance with rabies post exposure prophylaxis (PEP) in Côte d'Ivoire. Acta Tropica.

Tiembré, J.Benie Bi Vroh, Kouassi, P., et al., 2014. Connaissance, attitudes et pratiques en matière de rage à Abidjan. Santé Publique $26 \mathrm{~N} 4$ - juillet-août.

Wallace, et al., 2013. The impact of poverty on dog ownership and access to canine rabies vaccination:results from a knowledge, attitudes and practices survey, Uganda. Infect. Dis. Poverty 6, 972017.

World Health Organization. WHO expert consultation on rabies: first report. Technical Report Series No. 931, Geneva: The Organization; 2005.

WHO: https://www.who.int/fr/news-room/fact-sheets/detail/rabies consulté le 30 Décembre2019.

Zinsstag, J., Durr, S., Penny, M.A., Mindekem, R., Roth, F., Gonzalez, S.M., et al., 2009. Transmission dynamics and economics of rabies control in dogs and humans in an african city. Proc. Natl. Acad. Sci. U.S.A. 106 (35), 14996-15001 pmid:19706492. 